\title{
O PROGRAMA ENSINO INTEGRAL (PEI) DO ESTADO DE SÃO PAULO: ANÁLISE DAS PRODUÇÕES ACADÊMICAS
}

\author{
THE "FULL-TIME TEACHING PROGRAM" OF THE STATE \\ OF SÃO PAULO: ANALYSIS OF ACADEMIC PRODUCTIONS
}

EL PROGRAMA “ENSEÑANZA COMPLETA” DEL ESTADO DE
SÃO PAULO: ANÁLISIS DE LAS PRODUCCIONES ACADEMICAS

Cláudia da Mota Darós Parente ${ }^{1}$

Zelina Cardoso Grund ${ }^{2}$

Universidade Estadual Paulista "Júlio de Mesquita" (UNESP), São Paulo/SP-Brasil ${ }^{1}$

Universidade Estadual Paulista "Júlio de Mesquita” (UNESP), São Paulo/SP-Brasil²

Resumo O presente artigo analisa produções acadêmicas sobre o Programa Ensino Integral do Estado de São Paulo, sistematizando seus principais resultados. O Programa, criado em 2012, é destinado a alunos de escolas públicas do ensino fundamental e médio. Desde a sua criação, produziu várias alterações na gestão, no currículo e no trabalho docente. Por meio de levantamento bibliográfico em diferentes bases de dados, foram encontrados dezoito trabalhos acadêmicos produzidos entre 2015 e 2017. A análise das produções acadêmicas sobre o Programa Ensino Integral foi feita a partir de três dimensões: aspectos de sua implementação e gestão, aspectos curriculares e aspectos do trabalho docente. A maioria dos estudos possui abordagens qualitativas, com diversos focos de análise sobre o programa. Esta sistematização contribui para a análise da política educacional e indica a necessidade de ampliação de estudos sobre o Programa Ensino Integral com outras abordagens metodológicas e novos focos de análise.

Palavras-chave: Escola de Tempo Integral; Política Educacional; Programa Ensino Integral; São Paulo.

Abstract The article analyzes academic productions about the "Full-time Teaching Program" (PEI) of the State of São Paulo. The Program, created in 2012, is destined for students in primary and secondary public schools. Since its creation, it has produced several changes in the management, curriculum and teaching work. Through a bibliographic research in different databases, eighteen academic researches were founded, and they were 
produced between 2015 and 2017. The analysis of the academic researches about the "Fulltime Teaching Program" was made from three dimensions: aspects of its implementation and management, curricular aspects and aspects of the teaching work. Most of the studies have qualitative approaches, with several focuses of analysis about the program. This systematization contributes to the analysis of educational policy and indicates the need to expand studies on the "PEI" with other methodological approaches and new focus of analysis. Keywords: Full-Time School; "Full-time teaching" Program; Educational Policy; São PAULO.

Resumen El presente artículo analiza producciones académicas sobre el Programa "Enseñanza Completa" del Estado de São Paulo, sistematizando sus principales resultados. El Programa, creado en 2012, es destinado a alumnos de escuelas públicas de la enseñanza primaria y secundaria. Por medio de levantamiento bibliográfico en diferentes bases de datos, se encontraron dieciocho trabajos académicos producidos entre 2015 y 2017 . Desde su creación, ha producido varios cambios en la gestión, en el currículo y en el trabajo docente. El análisis de las producciones académicas sobre el Programa "Enseñanza Completa" se hizo a partir de tres dimensiones: aspectos de su implementación y gestión, aspectos curriculares y aspectos del trabajo docente. La mayoría de los estudios tienen enfoques cualitativos, con diversos focos de análisis sobre el programa. Esta sistematización contribuye para el análisis de la política educativa e indica la necesidad de ampliar estudios sobre el Programa "Enseñanza Completa" con otros enfoques metodológicos y nuevos focos de análisis. Palabras clave: Escuela de Tiempo Completo; Programa "Enseñanza Completa"; São PAULO.

\section{INTRODUÇÃo}

As experiências de educação em tempo integral vêm crescendo no Brasil, principalmente impulsionadas pela legislação nacional que, desde a aprovação da Lei de Diretrizes e Bases da Educação Nacional, Lei n. 9.394/1996 e, mais recentemente, com o Plano Nacional de Educação, Lei. 13.005/2014, tem feito indicações para a progressiva ampliação das matrículas e dos estabelecimentos em tempo integral (BRASIL, 1996; 2014).

No Brasil, conforme dados do Censo Escolar de 2016 (BRASIL, 2016), existiam 4.558.327 matrículas públicas em tempo integral na educação básica, representando $11 \%$ do total de matrículas nesta etapa do ensino, o que evidencia a necessidade de um esforço muito grande a ser feito por parte dos sistemas de ensino para atingir a meta de $25 \%$, conforme previsto no Plano Nacional de Educação (BRASIL, 2014).

No Estado de São Paulo, também no ano de 2016, das 7.287.728 matrículas públicas da educação básica, $14 \%$ eram em tempo integral. No que se refere à dependência administrativa, as matrículas em tempo integral, no Estado de São Paulo, estão majoritariamente sob a responsabilidade dos municípios. Os dados do Censo Escolar de 2016 mostram que a

1 Neste artigo, foram contabilizadas as matrículas públicas em tempo integral na Educação Básica, considerando os dados relativos ao ensino regular e/ou especial. 
oferta da educação básica pública paulista ocorre por meio das redes municipais de ensino ( $51 \%$ das matrículas) e da rede estadual (49\% das matrículas). Apesar disso, das 1.013 .058 matrículas públicas em tempo integral na educação básica, $74 \%$ estão sob a responsabilidade das redes municipais e $26 \%$ na rede estadual (BRASIL, 2016).

A rede estadual de ensino possui ao todo 261.921 matrículas públicas em tempo integral na educação básica, sendo: $33 \%$ concentradas no ensino médio, $48 \%$ nos anos finais do ensino fundamental; $18 \%$ nos anos iniciais do ensino fundamental; $1 \%$ na educação infantil (BRASIL, 2016).

Dados divulgados na página da Secretaria de Educação do Estado de São Pauloª apresentam informações mais específicas sobre a educação em tempo integral. Conforme o site, atualmente existem 48 mil alunos atendidos em 226 escolas integrantes do Projeto Escola de Tempo Integral (ETI) e 104 mil alunos atendidos em 308 escolas integrantes do Programa Ensino Integral (PEI). Além das duas políticas estaduais citadas, sabe-se que a rede estadual também aderiu ao Programa Mais Educação do Ministério da Educação.

O fato é que a ampliação das políticas de educação integral em tempo integral no Estado de São Paulo vem repercutindo nas produções acadêmicas. Ou seja, diante da formulação e da implementação do Programa Ensino Integral é preciso questionar: O que tem sido produzido sobre o Programa Ensino Integral? Quais os interesses dos pesquisadores? Como vêm conduzindo essas análises? Quais são os resultados fornecidos por esses estudos sobre o Programa Ensino Integral?

Diante desses questionamentos, o presente artigo tem como objetivo analisar as produções acadêmicas sobre o Programa Ensino Integral (PEI) do Estado de São Paulo, sistematizando seus principais resultados.

\section{ANÁlise das PROdUÇões ACADÊMICAS: PROCEDIMENTOS}

O presente artigo, ao buscar responder ao questionamento "o que tem sido produzido sobre o Programa Ensino Integral", pretende constituir-se no estado da arte sobre o PEI. Conforme Soares e Maciel (2000, p. 9), as pesquisas do tipo estado da arte ou estado do conhecimento "[...] podem conduzir à plena compreensão do estado atingido pelo conhecimento a respeito de determinado tema - sua amplitude, tendências teóricas, vertentes metodológicas". De acordo com Haddad (2002, p. 9), esses estudos permitem identificar "[...] temáticas e abordagens dominantes e emergentes, bem como, lacunas e campos inexplorados abertos à pesquisa futura". Assim, compreende-se a relevância do presente estudo tanto do ponto de vista acadêmico como do ponto de vista da análise de política pública.

Neste trabalho, para análise das produções acadêmicas sobre o Programa Ensino Integral (PEI) do Estado de São Paulo, foi realizada busca em diferentes Bases de Dados: Banco de Teses da Coordenação de Aperfeiçoamento de Pessoal de Nível Superior (CAPES) e 17 Bancos de Teses e Dissertações de universidades paulistas, priorizando-se as universidades com Programas de Pós-Graduação em Educação no Estado de São Paulo. A busca foi realizada em dezembro de 2017 e compreendeu o período entre 2012 (ano de criação do PEI) até 2017.

2 Informações disponíveis em: http://www.educacao.sp.gov.br/escola-tempo-integral. Acesso em: 24 abr. 2018. 
Na pesquisa, foram utilizados os seguintes termos de busca: educação integral, escola integral, tempo integral, escola de/em tempo integral, educação de/em tempo integral, jornada escolar, jornada integral, full-time school, full-time education, tiempo escolar, tiempo completo, ensino integral, programa ensino integral.

Conforme o Quadro 1, foram identificados dezoito trabalhos acadêmicos sobre o Programa Ensino Integral (PEI) do Estado de São Paulo, sendo duas teses de Doutorado e dezesseis dissertações de Mestrado. Os trabalhos acadêmicos foram produzidos e defendidos em treze instituições de educação superior, sendo doze do Estado de São Paulo e uma do Estado do Paraná. Entre as instituições nas quais os trabalhos foram defendidos, três eram públicas (Universidade Estadual Paulista - UNESP, Universidade Federal de São Carlos - UFSCar e Universidade Federal do Paraná) e dez privadas (Centro Universitário Moura Lacerda - CUML, Centro Universitário Salesiano de São Paulo - UNISAL, Pontifícia Universidade Católica de São Paulo - PUCSP, Universidade Cruzeiro do Sul - UCS, Universidade de Sorocaba - UNISO, Universidade de Taubaté - UNITAU, Universidade do Oeste Paulista - UNOESTE, Universidade Metodista de São Paulo - UMESP, Universidade Nove de Julho - UNINOVE, Universidade Presbiteriana Mackenzie - UPM).

Quadro 1: Produções Acadêmicas sobre o Programa Ensino Integral (PEI) do Estado de São Paulo - 2017.

\begin{tabular}{|l|l|l|l|l|}
\hline Ano & Autor & Tipo & Área & Instituição \\
\hline 2015 & Baptista & Dissertação & Educação & UNISAL \\
\hline 2015 & Caiuby & Dissertação & Educação & UNISO \\
\hline 2015 & Clemente & Dissertação & $\begin{array}{l}\text { Desenvolvimento Humano: } \\
\text { formação, políticas e práticas sociais }\end{array}$ & UNITAU \\
\hline 2015 & Danhão & Dissertação & Ensino de Ciências & UCS \\
\hline 2015 & Fodra & Dissertação & Educação & PUCSP \\
\hline 2015 & Quaresma & Dissertação & Profissional em Educação & PUCSP \\
\hline 2016 & Babalim & Dissertação & Educação & UNINOVE \\
\hline 2016 & Barbosa & Tese & Educação & PUCSP \\
\hline 2016 & Bengnozzi & Dissertação & Educação & CUML \\
\hline 2016 & Ferreira & Dissertação & Educação & UNOESTE \\
\hline 2016 & Pantaleoni & Dissertação & Educação, Arte e História da Cultura & UPM \\
\hline 2016 & Pessente & Dissertação & Profissional em Educação & UFSCar \\
\hline 2016 & Pinto & Dissertação & $\begin{array}{l}\text { Desenvolvimento Humano: } \\
\text { formação, políticas e práticas sociais }\end{array}$ & UNITAU \\
\hline 2017 & Alves & Dissertação & $\begin{array}{l}\text { Desenvolvimento Humano: } \\
\text { formação, políticas e práticas sociais }\end{array}$ & UNITAU \\
\hline 2017 & Oliveira & Dissertação & Educação & UNESP \\
\hline 2017 & Ostler & Tese & Educação & UMESP \\
\hline 2017 & Remião & Dissertação & Comunicação & UFPR \\
\hline 2017 & Santos & Dissertação & Profissional em Educação & \\
\hline
\end{tabular}

Elaborado pelas autoras. 
Dos dezoito trabalhos encontrados, seis foram defendidos em 2015, sete em 2016 e cinco em 2017. No que se refere à área de conhecimento, com base na classificação da CAPES, o levantamento indicou a existência de: doze trabalhos na área de Educação, sendo três trabalhos de Mestrado Profissional; três na área de Desenvolvimento Humano; um na área de Ensino de Ciências; um na área de Educação, Arte e História; um na área de Comunicação.

Após a análise descritiva das produções acadêmicas, procedeu-se à leitura dos trabalhos na íntegra, contando com o apoio de alguns aspectos da técnica de análise de conteúdo (AMADO; COSTA; CRUSOÉ, 2014). Nessa etapa, a análise dos trabalhos acadêmicos selecionados privilegiou a apreensão dos seguintes elementos: objetivos/focos de análise, procedimentos metodológicos e resultados. Além disso, a análise foi feita com base em três categorias: aspectos da implementação e da gestão do PEI; aspectos curriculares do PEI e aspectos do trabalho docente no PEI.

Em relação aos aspectos metodológicos, identificou-se que, dos dezoito trabalhos acadêmicos analisados, dezessete realizaram pesquisa de campo e se debruçaram sobre aspectos da realidade vivenciada por meio da implementação do Programa Ensino Integral. Somente um trabalho optou por fazer apenas pesquisa bibliográfica e documental sobre o PEI.

Os dezessete trabalhos que fizeram pesquisa de campo utilizaram diferentes procedimentos/instrumentos para coleta de dados, entre eles, questionários, entrevistas, observações e grupo focal. No que se refere aos sujeitos da pesquisa, o PEI tem sido analisado, conforme mostra a maior parte dos estudos, sob o prisma, exclusivamente, dos professores (nove). Além disso, foram encontrados: quatro trabalhos que se preocuparam em analisar o PEI na perspectiva dos diferentes atores da escola (gestores, professores e alunos); dois trabalhos cujos sujeitos foram os gestores, aqui incluídos diretores e coordenadores pedagógicos; um trabalho com foco na análise do papel dos supervisores de ensino em relação ao programa; um trabalho com foco na análise das concepções dos alunos sobre o PEI.

No que se refere à temática/foco dos trabalhos acadêmicos, não foi objetivo desta análise verificar se os pesquisadores desenvolveram buscas prévias sobre a existência de trabalhos anteriores sobre o PEI. No entanto, é possível inferir que, no período de 2015 a 2017, o Programa Ensino Integral (PEI) do Estado de São Paulo foi analisado a partir de vários enfoques. A diversidade de foco de análise do Programa indica que os pesquisadores têm feito estudos com diferentes objetivos e essa variedade temática é importante não apenas do ponto de vista acadêmico, mas também do ponto de vista da política pública, já que mostra que o PEI, como ação governamental, tem sido analisado por meio de diferentes prismas.

Neste artigo, para fins de exposição do estado da arte sobre o Programa Ensino Integral, após a descrição dos principais aspectos legais do programa, optou-se por fazer uma análise dos trabalhos acadêmicos com base nas três categorias elencadas anteriormente: aspectos da implementação e da gestão do PEI; aspectos curriculares do PEI; aspectos do trabalho docente no PEI.

\section{O Programa de Ensino Integral (PEI) do Estado de São Paulo}

Em 2011, o governo do Estado de São Paulo criou o Programa Educação Compromisso de São Paulo, instituído pelo Decreto n. 57.571. Entre as principais diretrizes do referido Programa pode-se citar: 
I - valorização da carreira do magistério [...]; II - melhoria da atratividade e da qualidade do ensino médio [...]; III - atendimento prioritário às unidades escolares cujos alunos apresentem resultados acadêmicos insatisfatórios [...]; IV - emprego de tecnologias educacionais nos processos de ensino-aprendizagem; V - mobilização permanente dos profissionais da educação, alunos, famílias e sociedade [...]. (SÃO PAULO, 2011, art. $2^{\circ}$ )

No contexto do Programa Educação Compromisso de São Paulo, por meio da Lei Complementar n. 1.164/2012, foram instituídos o Regime de Dedicação Plena e Integral (RDPI) e a Gratificação de Dedicação Plena e Integral (GDPI) aos integrantes do quadro do Magistério em exercício nas escolas estaduais de ensino médio de período integral. A referida lei faz menção às "Escolas Estaduais de Ensino Médio de Período Integral", caracterizando-as como

[...] unidades escolares de ensino médio de turno integral, que têm como objetivo a formação de indivíduos autônomos, solidários e produtivos, com conhecimentos, valores e competências dirigidas ao pleno desenvolvimento da pessoa humana e seu preparo para o exercício da cidadania, mediante conteúdo pedagógico, método didático e gestão curricular e administrativa próprios, conforme regulamentação, observada a Base Nacional Comum, nos termos da lei. (SÃO PAULO, 2012a, art. 2º)

No âmbito da Secretaria de Educação, por meio da Resolução SE n. 12/2012 (SÃO PAULO, 2012b), foi instituído o "Projeto Escola Estadual de Ensino Médio de Período Integral". Uma análise documental atenta permitiu verificar que, mesmo em andamento, a Secretaria de Educação ainda não nomeava oficialmente tais ações de ampliação da jornada escolar no ensino médio de "Programa Ensino Integral". Esse nome surgiu apenas com a aprovação da Lei Complementar 1.191/2012, que alterou a Lei Complementar 1.164/2012, ou seja, quase um ano após o início das ações. A Lei Complementar 1.191/2012 dispõe, portanto, sobre o Programa Ensino Integral em escolas estaduais, “[...] podendo o Ensino Integral ser oferecido em unidades escolares de ensino fundamental e/ou médio" (SÃO PAULO, 2012c, art. $6^{\circ}$ ).

No que se refere à equipe escolar, inicialmente, nas escolas do PEI, foram designados profissionais efetivos para as seguintes funções: "[...] 1 - Diretor de Escola; 2 - Vice-Diretor de Escola; 3 - Professor Coordenador Geral; 4 - Professor Coordenador por área de conhecimento; 5 - Professor de Sala de Leitura" (SÃO PAULO, 2012c, art. $3^{\circ}$ ). Mais adiante, com a Resolução SE 67/2014, o quadro de pessoal das escolas do Programa Ensino Integral passou a ser formado por:

I - 1 (um) Diretor de Escola;

II - 1 (um) Vice-Diretor de Escola;

III - 1 (um) Professor Coordenador Geral (PCG);

IV - 1 (um) Professor Coordenador por Área de Conhecimento;

V - 1 (um) Professor responsável pela Sala/Ambiente de Leitura;

VI - Professores em exercício exclusivo de atividades docentes. (SÃO PAULO,

2014a, art. $2^{\circ}$ ) 
A princípio, a Lei Complementar n. 1.164/2012 instituiu aos profissionais do PEI a Gratificação de Dedicação Plena e Integral - GDPI, correspondente a 50\% “[...] do valor da faixa e nível da Estrutura da Escala de Vencimentos em que estiver enquadrado o cargo ou a função-atividade do integrante do Quadro do Magistério", submetidos ao "Regime de Dedicação Plena e Integral - RDPI (SÃO PAULO, 2012a, art. 11). Posteriormente, a Lei Complementar n. 1.191/2012 alterou o percentual para 75\% (SÃO PAULO, 2012c, art. 11).

Em termos legais, pode-se também citar o Decreto n. 59.354/2013 que, entre outros aspectos, trata do quadro de pessoal que integrará as escolas que fazem parte do Programa Ensino Integral. Para integrar a equipe escolar das escolas que aderiram ao PEI, deve-se participar de processo seletivo que, entre outros requisitos, exige que o professor seja efetivo da rede há, no mínimo, três anos (SÃO PAULO, 2013a, art. $5^{\circ}$ ).

A Resolução SE n. 49/2013 definiu que os profissionais do magistério que trabalham nas escolas que aderiram ao PEI possuem uma carga horária de oito horas diárias, ou seja, quarenta horas semanais, sendo que "[...] a carga horária dos docentes nas escolas do Programa Ensino Integral compreenderá obrigatoriamente as disciplinas da Base Nacional Comum, da Parte Diversificada e das Atividades Complementares" (SÃO PAULO, 2013b, art. 15).

Após o credenciamento dos profissionais no Programa, processa-se a avaliação do desempenho, normatizada pela Resolução SE n. 84/2013, dada a necessidade de determinar critérios para assegurar a "[...] eficácia, legitimidade e transparência no processo dos servidores em Regime de Dedicação Plena e Integral (RDPI), participantes do Programa Ensino Integral" (SÃO PAULO, 2013c).

A Resolução SE n. 49/2013 descreve com detalhes a organização e o funcionamento das escolas estaduais integrantes do Programa, respeitando as prescrições das legislações citadas e suas alterações (SÃO PAULO, 2013b).

Assim, no que se refere à gestão pedagógica e administrativa do Programa Ensino Integral, alguns elementos são essenciais:

I - Carga Horária Discente - o conjunto de aulas dos diferentes componentes curriculares que compõem a Base Nacional Comum, a Parte Diversificada e as Atividades Complementares;

II - Carga Horária Multidisciplinar Docente - o conjunto de horas em atividades com alunos e de horas de trabalho pedagógico, coletivo e individual, cumprido exclusivamente na escola do Programa Ensino Integral, promovendo a integração das áreas de conhecimento da Base Nacional Comum, da Parte Diversificada e das Atividades Complementares;

III - Carga Horária de Gestão Especializada - o conjunto de horas em atividades de gestão, suporte e eventual atuação pedagógica, exercidas exclusivamente pelo diretor e vice-diretor na escola do Programa Ensino Integral, conforme plano de ação estabelecido;

IV - Projeto de Vida - o documento elaborado pelo aluno, que expressa metas e define prazos, com vistas à realização das aptidões individuais, com responsabilidade individual, social e institucional em relação à Escola Estadual do Programa Ensino Integral; 
V - Protagonismo juvenil - o processo pedagógico no qual o aluno é estimulado a atuar criativa, construtiva e solidariamente na solução de problemas reais na escola, na comunidade e na vida social;

VI - Clubes juvenis - os grupos temáticos, criados e organizados pelos alunos, com apoio dos professores e da direção da escola;

VII- Tutoria - o processo didático-pedagógico destinado a acompanhar, orientar o projeto de vida do aluno, bem como, propiciar atividades de recuperação, se necessário. (SÃO PAULO, 2013b, art. 2º)

Quanto ao corpo discente do Programa Ensino Integral, os alunos do Ensino Médio possuem uma carga horária de até nove horas e trinta minutos e o alunos de Ensino Fundamental até oito horas e quarenta minutos, com um intervalo de 1 a $1 \mathrm{~h} 30$ de almoço e dois intervalos de 15 minutos (manhã e tarde) (SÃO PAULO, 2013b, art. 13).

Para a orientação dos profissionais integrantes do Programa de Ensino Integral, a Secretaria de Estado da Educação de São Paulo elaborou vários documentos que expressam, entre outros elementos: a concepção do programa, o modelo pedagógico de ensino integral, metodologia do PEI, gestão de desempenho no PEI, subsídios para as ações de formação continuada e avaliação da aprendizagem no contexto do PEI (SÃO PAULO, s.d.; 2014b; 2014c; 2014d; 2014e; 2014f; 2014g).

A partir das referências legais apresentadas, pode-se destacar alguns aspectos principais do Programa Ensino Integral (PEI): 1) conjunto de diretrizes político-administrativas e pedagógicas que recaem sobre a escola e seus atores, o que implica a necessidade de analisar seu processo de implementação; 2) conjunto de alterações pedagógico-curriculares, o que resulta na importância de analisar como ocorreram tais alterações e seus reflexos na escola e em seus sujeitos; 3) conjunto de medidas que alteram o trabalho e a remuneração dos profissionais que atuam no PEI, o que mostra a relevância de analisar tais aspectos e suas consequências para a escolas e seus sujeitos. Esses três aspectos serão analisados a partir do que se produziu sobre o PEI entre 2015 e 2017.

\section{Aspectos da implementaÇão e da gestão do Programa Ensino Integral (PEI)}

Tomando-se como referência o campo de análise de políticas públicas, é importante que toda ação governamental e, portanto, toda política pública, em suas diferentes fases (agenda, formulação, implementação, avaliação), seja monitorada e analisada sob os mais diversos prismas (PARENTE, 2018a). Assim, estando o Programa Ensino Integral em processo de implementação na rede estadual de ensino de São Paulo, é importante que esteja sendo analisado, ademais de outras formas, na instância acadêmica. Como se viu, é evidente o interesse dos pesquisadores em tomá-lo como objeto de estudo. Nesta parte do artigo, importa mostrar as principais opções dos pesquisadores ao tomar o PEI como objeto de estudo e, diante de tais opções, seus principais resultados.

A pesquisa identificou oito trabalhos acadêmicos cujos resultados podem contribuir, mais especificamente, para a análise da implementação e da gestão do Programa Ensino Integral (PEI) do Estado de São Paulo. 
Primeiramente, cabe destacar que cada pesquisador faz suas opções metodológicas e seleciona seu cenário de estudo, ou seja, o local no qual deseja evidenciar a repercussão do PEI. Assim, em termos de cenário de estudo, identificamos que poucos estudos analisaram o PEI a partir de cenários mais amplos, como foi o caso da pesquisa de Santos (2017), que estudou diretores de escolas estaduais do município de São José do Rio Preto, e a pesquisa de Clemente (2015), que focalizou seu estudo numa Diretoria da região do Vale do Paraíba. Grande parte dos estudos optou por análises de experiências escolares: Baptista (2015) analisou uma escola no município de Piracicaba; Caiuby (2015) focalizou uma escola de Sorocaba; Pinto (2016) analisou uma escola do Vale do Paraíba; Ostler (2017) centrou sua análise em escolas da Baixada Santista; Quaresma (2015) e Barbosa (2016) analisaram o PEI em escolas da capital.

Estudos de implementação de políticas públicas podem ter diferentes objetivos. Os cenários de pesquisa citados anteriormente demarcam interesses por uma abordagem mais qualitativa, centrando a análise da implementação no âmbito das escolas. Por isso, há uma tendência em privilegiar a análise da implementação do ponto de vista dos sujeitos implementadores das políticas: professores, diretores, supervisores, alunos.

Muitas políticas, após implementadas ou em implementação, passam por um processo de análise e avaliação. Muitas vezes, há dificuldades, inclusive metodológicas, de isolar o que é consequência da política e o que são aspectos anteriores a ela. Assim, nesse exercício de análise das produções acadêmicas, foi possível perceber que muitos resultados identificados como consequências do PEI, na realidade, são consequências de um cenário político-administrativo mais amplo e anterior ao próprio programa, conforme mostram estudos que analisam as políticas educacionais da rede estadual de ensino de São Paulo nas últimas décadas (NOVAES, 2009; RAMOS, 2016; PARENTE, 2016).

A pesquisa de Clemente (2015), por exemplo, faz menção ao papel do supervisor escolar no contexto do PEI. Há algum tempo se discute os dilemas da ação supervisora, entre eles, a dicotomia burocrático-administrativo e pedagógico. No entanto, esse dilema, anterior ao PEI, acentua-se em função das demandas burocráticas do programa. Por sua vez, a pesquisa de Ostler (2017) focaliza o impacto do PEI nos alunos da educação especial. O programa, ao criar uma nova dinâmica escolar, não pensou nas especificidades e necessidades dos alunos de inclusão. Novamente, cabe destacar: o dilema da inclusão, anterior ao PEI, acaba sendo desconsiderado pela política em vigor ou mesmo reforçado.

É também relevante mencionar a pesquisa de Santos (2017), cujo foco recaiu sobre a Avaliação $360^{\circ}$ na visão dos diretores, estratégia específica do PEI. Num contexto mais amplo, a avaliação do desempenho tem sido tratada como aspecto intrínseco de muitas políticas em vigor, tendo em vista a disseminação do conceito de performatividade, por exemplo. O PEI, ao oferecer gratificação e dedicação exclusiva, aspectos carregados de positividade, parece, ao mesmo tempo, fortalecer ainda mais os vínculos entre performatividade e avaliação. A pesquisa citada traz evidências de que essa cultura de avaliação vinculada à performatividade deveria ser substituída por uma cultura de avaliação ressignificada no âmbito da escola, com seu coletivo, de acordo com sua materialidade e articulada a uma proposta pedagógica. 
As pesquisas de Baptista (2015) e de Quaresma (2015) fazem análises específicas sobre a gestão escolar. O estudo de Baptista (2015) contribui com reflexões sobre as consequências do modelo de gestão do PEI no cotidiano da gestão escolar. Diante de episódios vivenciados pela gestora escolar, tece pertinentes comentários e questionamentos. Por sua vez, há que destacar a investigação de Quaresma (2015), que analisa a gestão democrática numa escola com PEI. Após a análise do estudo, pode-se inferir que um determinado modelo de gestão pode atuar como diferencial na implementação de um programa; ao mesmo tempo, um programa, a exemplo do PEI, pode criar determinadas condições (a exemplo da dedicação exclusiva dos profissionais que atuam na escola) para o fortalecimento das relações e dos espaços coletivos e, por conseguinte, da gestão democrática da escola.

É imprescindível que os sujeitos implementadores não sejam reprodutores das políticas públicas em vigor; é importante que os sujeitos, principalmente no âmbito das escolas, possam ressignificar as políticas. Daí a relevância da formação continuada no âmbito da escola, a fim de que seus sujeitos possam, continuamente, refletir sobre seu papel, sua atuação, o cenário externo e as demandas por uma formação integral. A pesquisa de Barbosa (2016) vai justamente nessa direção ao defender que os sujeitos ressignifiquem o espaço escolar, sejam protagonistas e participem na construção do projeto político-pedagógico. As pesquisas mostram que, em relação a esse aspecto, o PEI atua como facilitador em função de seus profissionais terem dedicação exclusiva.

No entanto, mais além de um processo de ressignificação da política por parte dos sujeitos, estão as condições materiais para sua operacionalização. Mais uma vez, cabe destacar os aspectos anteriores à própria política, ou seja, as condições materiais, por exemplo, nas quais elas são implementadas. As pesquisas mostraram, a exemplo do estudo de Caiuby (2015), que no processo de implementação do PEI ainda existem problemas de materialidade que inibem a consecução dos objetivos da política. Essa parece ser a característica de muitas políticas públicas na área da educação, ou seja, são previstos objetivos que não podem ser alcançados em função de não se alteraram as condições materiais nas quais serão operacionalizados.

Apesar desse cenário, a pesquisa de Pinto (2016), ancorada na percepção dos sujeitos-alunos, mostra um contexto mais estruturado, no qual infraestrutura, coletividade e currículo atuam como fatores que, no PEI, têm contribuído para uma escola de qualidade.

Assim, os trabalhos acadêmicos analisados oferecem alguns elementos para compreender como o PEI tem sido implementado. Entende-se que muitos de seus limites estão vinculados a situações preexistentes. Há também evidências de que o PEI, no seu desenho e modelo de gestão, tem reproduzido lógicas que não são suas de forma exclusiva, perpetuando características já presentes em outras políticas educacionais da rede estadual, a exemplo daquelas relacionadas ao gerencialismo e à performatividade.

Apesar disso, os estudos revelaram que, mesmo diante dessas lógicas, os sujeitos implementadores têm feito ressignificações, aproveitando aspectos positivos da política, a exemplo da dedicação exclusiva e da jornada em uma única escola, para recriar a política no âmbito da escola. Ou seja, os "sujeitos, também atores nos cenários das mais diferentes 
políticas educacionais, são também, em certa medida, (re)formuladores da política pública" (PARENTE, 2018b, p. 344).

Assim, a análise dos trabalhos acadêmicos mostrou que, em termos de estado da arte e no âmbito da implementação e gestão do PEI, muitos aspectos já foram alvo de interesses acadêmicos, o que reverbera no conhecimento acumulado sobre o programa. No entanto, há ainda muitas possibilidades de análise no que se refere aos aspectos de implementação e da gestão do PEI, a exemplo de estudos no campo de análise de políticas públicas, de investigações com abordagens quanti-qualitativas e de estudos no campo da educação comparada.

\section{Aspectos curriculares do Programa Ensino Integral (PEI)}

Ao longo de todo o século XX e começo do século XXI, surgiram diferentes experiências de ampliação da jornada escolar. A ampliação da jornada escolar tem relação direta com a organização do currículo escolar. Conforme citado, a legislação sobre o PEI aponta para uma reconfiguração do currículo escolar. Às disciplinas/componentes curriculares da Base Comum Curricular somam-se disciplinas/componentes curriculares da Parte Diversificada. Entre as novidades do PEI estão: orientações de estudos, projeto de vida, protagonismo juvenil, preparação acadêmica, mundo do trabalho.

Neste artigo, importa destacar como os trabalhos acadêmicos têm analisado o PEI e sua estrutura curricular. Mais ainda, como têm feito suas opções metodológicas e os principais resultados evidenciados.

A pesquisa identificou cinco trabalhos acadêmicos que se preocuparam mais diretamente com os aspectos curriculares do Programa Ensino Integral (PEI) ou no seu contexto de implementação. Das cinco pesquisas, apenas uma não realizou pesquisa de campo.

A investigação de Bengnozzi (2016) privilegiou a análise dos documentos oficiais do programa e buscou traçar evidências dos vínculos do PEI com o Programa "Educação Compromisso de São Paulo", assim como, dos vínculos da concepção de currículo do PEI com aspectos disseminados no contexto atual: capital humano, protagonismo, responsabilização, resultado, competência e polivalência.

Esse tipo de investigação, centrada na análise documental, pode mostrar como foi o processo de formulação do PEI, seus argumentos, aspectos legais e concepções dos formuladores. No entanto, apenas as investigações que fizeram pesquisa de campo trouxeram elementos mais detalhados sobre o processo de implementação do PEI e o currículo no âmbito das escolas. Por sua vez, há que destacar que os focos de investigação foram bastante específicos e não abarcam a totalidade das alterações curriculares promovidas pelo PEI.

O trabalho de Pantaleoni (2016) teve como objetivo analisar o papel da Arte no PEI; a investigação de Ferreira (2016) focalizou o Programa Sala de Leitura no contexto de implementação do PEI; Fodra (2015) focou no componente curricular Projeto de Vida e sua relação com as aulas de História; Danhão (2015) analisou a utilização do software hagáquê (HQ) numa escola com PEI. Assim, conclui-se que, das quatro pesquisas citadas, apenas uma analisou um aspecto curricular próprio do PEI: o Projeto de Vida (FODRA, 2015). 
Conforme destacado, o Projeto de Vida é um dos componentes curriculares do Programa Ensino Integral (PEI). Fodra (2015), ao analisá-lo, evidenciou que as aulas de Projeto de Vida têm um papel importante na formação e no desenvolvimento dos alunos.

Com base na legislação e na análise dos trabalhos acadêmicos, sabe-se que o Programa Ensino Integral estabelece mudanças importantes no currículo, as quais possibilitam novas perspectivas em relação à compreensão do sujeito-aluno e em relação ao papel do professor. Apesar disso, tomando-se como referência as pesquisas analisadas, ainda existem muitas lacunas no que se refere aos aspectos curriculares do PEI. Assim, em termos de foco de análise, sugere-se que sejam feitas análises mais profundas sobre as alterações curriculares promovidas pelo programa. Do ponto de vista metodológico, talvez seja interessante a realização de análises comparativas do Programa em diferentes contextos ou em relação a outras políticas, a fim de que seja possível visualizar diferentes opções de desenho curricular.

\section{Aspectos do trabalho docente no Programa Ensino Integral (PEI)}

Não obstante as determinações legais em vigor relativas à jornada de trabalho e à remuneração dos profissionais da educação (BRASIL, 2008; 2014), há muito ainda a avançar para que se efetive uma real valorização dos profissionais da educação.

No contexto atual, políticas de alteração da jornada escolar vêm sendo implementadas nos últimos anos, trazendo à tona contrapontos entre jornada parcial e jornada integral do aluno. Diferentemente de outras políticas que alteram a jornada escolar do aluno, o PEI inova ao articular jornada ampliada de aluno à jornada ampliada de professor. No desenho do PEI dois aspectos são essenciais: dedicação integral do profissional numa única escola e gratificação por atuação no programa. Apesar de o PEI ser uma política residual e, portanto, não atingir a totalidade dos profissionais da rede estadual de ensino, é imprescindível analisar como esses elementos de estímulo - melhoria da remuneração e das condições de trabalho - repercutem nos contextos de implementação e em seus sujeitos.

Neste artigo, interessa destacar como as pesquisas acadêmicas aproximaram-se das questões relativas ao trabalho docente e das alterações promovidas pelo PEI, suas opções metodológicas e principais resultados. O levantamento indicou cinco trabalhos a partir dos quais é possível analisar aspectos do trabalho docente no PEI, embora num dos trabalhos a atuação docente não tenha sido analisada a partir de alterações promovidas pelo programa e sim utilizando o PEI como contexto de análise. É o caso da pesquisa de Remião (2017), que analisou a educomunicação numa escola com PEI. Para a autora, os clubes juvenis e as disciplinas eletivas (estratégias específicas do PEI) seriam ricas oportunidades pedagógicas, porém não têm sido bem utilizadas.

Do ponto de vista metodológico, os trabalhos privilegiaram abordagens qualitativas, com coleta de informações em cenários específicos (uma ou mais escolas) e com foco no sujeito-professor.

As pesquisas de Alves (2017) e Babalim (2016) focalizaram a percepção e as expectativas dos professores e ressaltaram a importância da jornada integral e da dedicação exclu- 
siva numa única escola, aspectos que possibilitam o trabalho coletivo e o estreitamento das relações entre os diferentes sujeitos da escola. Como consequência, tais aspectos refletem na valorização dos profissionais da educação, formação dos alunos e, portanto, na qualidade da escola.

A pesquisa de Pessente (2016) auxilia na compreensão de um aspecto importante que o PEI denomina "professor protagonista", ou seja, aquele profissional que se assume como agente de mudança e que segue em contínuo processo de formação e atualização e que, por conseguinte, promoverá uma formação de qualidade aos seus alunos. No entanto, a autora acredita que esse protagonismo precisa estar associado a um processo contínuo de formação e que a própria Secretaria de Educação também seja protagonista nessa ação.

Por fim, deve-se citar a pesquisa de Oliveira (2017), que reforça a ideia de que o PEI insere-se num contexto de intensificação do trabalho docente. Apesar da jornada integral do professor numa única escola, aspecto positivo do programa, é preciso compreender as novas demandas burocráticas e administrativas exigidas ao professor. Além disso, conforme citado, o PEI é parte de políticas educacionais mais amplas, caracterizadas como gerencialistas e performáticas, o que remete à ideia de intensificação do trabalho docente.

A análise dos trabalhos acadêmicos permitiu identificar que o Programa Ensino Integral, não apenas no âmbito legal mas também na prática, produz alterações na jornada de trabalho docente em função do Regime de Dedicação Plena e Integral (RDPI) e da gratificação articulada ao programa. Os trabalhos acadêmicos não se dedicaram com profundidade à questão, demarcando evidências de que há ainda muitas possibilidades de análise do trabalho docente no âmbito do PEI, a exemplo de pesquisas com abordagens quanti-qualitativas. Talvez seja relevante captar de forma mais sistematizada as consequências da jornada integral na qualidade da ação docente. Além disso, embora a gratificação não seja parte da remuneração efetiva do professor (não permanente), seria importante mostrar evidências de como uma boa remuneração pode trazer consequências importantes na atuação do profissional da educação.

\section{CONSIDERAÇÕES FINAIS}

O presente artigo teve como objetivo analisar as produções acadêmicas sobre o Programa Ensino Integral (PEI) do Estado de São Paulo, criado em 2012. O levantamento realizado em diferentes Bases de Dados indicou a existência de dezoito trabalhos sobre o Programa, produzidos em diferentes instituições entre 2015 e 2017. A maior parte dos estudos optou por abordagens qualitativas, coletando informações junto a diferentes sujeitos da educação (gestores, professores, alunos).

Diante dos objetivos desse tipo de estudo, com foco no estado do conhecimento até então produzido sobre o Programa Ensino Integral, o artigo privilegiou três eixos de análise: aspectos da implementação e da gestão do PEI, aspectos curriculares do PEI e aspectos do trabalho docente no PEI.

No que tange à implementação e à gestão do PEI, a análise mostrou que o programa articula-se a um modelo de gestão empresarial que compreende, entre outros elementos: 
monitoramento sistemático, avaliação de desempenho e modelo pedagógico específico. Esses aspectos vinculam-se às características gerencialistas das políticas educacionais formuladas e implementadas no Estado de São Paulo nas últimas décadas. Apesar disso, nem sempre as escolas nas quais o programa foi implementado possuíam condições materiais adequadas para sua execução, o que indica que problemas preexistentes à política podem influenciar o contexto de implementação. Ademais, os estudos mostraram que alguns gestores conseguiram desenvolver um trabalho diferenciado, por meio da gestão participativa e do fortalecimento das relações com os educandos, famílias e comunidade, aspectos que também fazem parte das diretrizes do programa. Essa situação demarca a necessidade de não interpretar o processo de implementação como mera reprodução das intencionalidades de seus formuladores e sim como releituras no âmbito de cada contexto educativo.

Quanto aos aspectos curriculares, os estudos fizeram apontamentos sobre algumas especificidades do modelo pedagógico proposto pelo PEI e de alguns aspectos curriculares. As investigações destacaram o papel dos professores como mediadores no desenvolvimento de atividades que favoreçam, por exemplo, o protagonismo juvenil e o projeto de vida do aluno. No entanto, a análise dos trabalhos acadêmicos apontou a importância de realizar estudos que, com maior profundidade, privilegiem aspectos curriculares próprios do PEI e sob diferentes abordagens.

No que se refere aos aspectos do trabalho docente no Programa Ensino Integral, é relevante o fato de que os professores possuem jornada de trabalho numa única escola, em Regime de Dedicação Plena e Integral e com gratificação na remuneração. Esse contexto, evidenciado pelas pesquisas, favorece a atuação do que o programa chama de "professor protagonista". Apesar disso, alguns estudos apontam a necessidade de maior apoio da Secretaria de Educação na ampliação de processos formativos para que isso realmente ocorra. Além disso, outros estudos mostram que, apesar da jornada em RDPI propiciar o trabalho numa única escola e favorecer o trabalho coletivo, ela também pode levar à intensificação do trabalho docente. Diante do cenário investigativo, é importante que novos estudos sejam feitos, de forma a captar impactos das especificidades do Programa na ação docente num contexto mais abrangente.

Com base nas pesquisas analisadas e diante do estado da arte sobre o PEI, conclui-se que, apesar das contribuições dos trabalhos acadêmicos produzidos até o momento, ainda existem muitas possibilidades de análise do programa como política pública em implementação na rede estadual de ensino de São Paulo. É preciso analisar com maior profundidade aspectos intrínsecos do programa, bem como, sua repercussão nos contextos de implementação e nos sujeitos. Ademais, são importantes investigações com apreendam o objeto de estudo "PEI" sob os mais diferentes procedimentos metodológicos, entre eles, aqueles relacionados ao campo de análise de políticas públicas. 


\section{REFERÊNCIAS}

ALVES, Aretusa Vanessa Melissa. Implicações do Programa Ensino Integral para o trabalho docente: o olhar dos professores. 2017. 149 f. Dissertação (Mestrado em Desenvolvimento Humano: Formação, Políticas e Práticas Sociais) - Universidade de Taubaté, Taubaté, 2017.

AMADO, João; COSTA, António Pedro; CRUSOÉ, Nilma. Procedimento de análise de dados. In: AMADO, João (coord.). Manual de investigação qualitativa em educação. Coimbra: Imprensa da Universidade de Coimbra, 2014. p. 299-352.

BABALIM, Valéria de Souza. Escola de tempo integral: relato de uma experiência na rede estadual de ensino de São Paulo. 2016.154 f. Dissertação (Mestrado em Educação) Universidade Nove de Julho, São Paulo.

BARBOSA, Rafael Conde. Aprendizagens e relações no tempo e espaço escolares: suas ressignificações no contexto do Programa de Ensino Integral do Estado de São Paulo (PEI). 2016.136 f. Tese (Doutorado em Educação: Psicologia da Educação) - Pontifícia Universidade Católica de São Paulo, São Paulo, 2016.

BAPTISTA, Flávia Fernanda Consentino Modolo Esteves. Educação e ensino integral e a gestão escolar: tempos e contratempos. 2015. 100 f. Dissertação (Mestrado em Educação) - Centro Universitário Salesiano de São Paulo - UNISAL, Americana, 2015.

BENGNOZZI, Eliana Aparecida. O Programa Ensino Integral nas escolas de Ensino Médio do Estado de São Paulo: a disciplina Projeto de Vida como eixo central. 2016. 149

f. Dissertação (Mestrado em Educação). Centro Universitário Moura Lacerda. Ribeirão Preto, 2016.

BRASIL. Lei n. 9.394, de 20 de dezembro de 1996. Lei de Diretrizes e Bases da Educação. Disponível em: http://www.planalto.gov.br/ccivil_03/leis/L9394.htm. Acesso em: 01 maio 2018.

BRASIL. Lei n. 13.005, de 25 de junho de 2014. Plano Nacional de Educação - 2014-2014. Disponível em: http://www2.camara.leg.br/legin/fed/lei/2014/lei-13005-25-junho-2014-778970-publicacaooriginal-144468-pl.html. Acesso em: 01 maio 2018.

BRASIL. Sinopse Estatística da Educação Básica 2016. Disponível em: http://inep.gov. br/sinopses-estatisticas-da-educacao-basica Acesso em: 01 maio 2018.

BRASIL. Lei n. 11.738, de 16 de julho de 2008. Regulamenta a alínea "e" do inciso III do caput do art. 60 do Ato das Disposições Constitucionais Transitórias, para instituir o piso salarial profissional nacional para os profissionais do magistério público da educa- 
ção básica. Disponível em: http://www.planalto.gov.br/ccivil_03/_ato2007-2010/2008/lei/ 111738.htm. Acesso em: 28 mar. 2019.

CAIUBY, Bianca Barrochelo. Educação de tempo integral: entre entraves e possibilidades. 2015. 129 f. Dissertação (Mestrado em Educação) - Universidade de Sorocaba, Sorocaba, 2015.

CLEMENTE, Vanilda Aparecida Pereira da Silva. Ação supervisora nas escolas do Programa Ensino Integral da rede estadual de São Paulo. 2015. 128 f. Dissertação (Mestrado em Desenvolvimento Humano: Formação, Políticas e Práticas Sociais) - Universidade de Taubaté, Taubaté, 2015.

DANHÃO, Elizabeth Aparecida Assis Brandão. O uso do hagáquê (hq) como facilitador no processo de ensino e aprendizagem em uma escola do Programa de Ensino Integral. 2015. 150 f. Dissertação (Mestrado em Ensino de Ciências) - Universidade Cruzeiro do Sul, São Paulo, 2015.

FERREIRA, Homéro. O perfil do professor como responsável pelo "Programa Sala de Leitura" em escolas públicas de uma cidade do Oeste Paulista: formação docente e práticas de mediação. 2016. 158 f. Dissertação (Mestrado em Educação) - Universidade do Oeste Paulista, Presidente Prudente, 2016.

FODRA, Sandra Maria. O projeto de vida no ensino médio: o olhar dos professores de História. 2016. 175 f. Dissertação (Mestrado em Educação) - Pontifícia Universidade Católica de São Paulo, São Paulo, 2016.

HADDAD, Sérgio. Introdução. In: Educação de jovens e adultos no Brasil (1986-1998). Brasília: MEC/Inep/ Comped, 2002. p. 9-19. (Série Estado do Conhecimento, n. 8).

NOVAES, L. C. Os impactos da política educacional paulista na prática docente e na organização do trabalho pedagógico nas escolas estaduais paulistas na perspectiva dos professores. Jornal de Políticas Educacionais, Curitiba, n. 5, p. 13-26, jan./jun. 2009.

OLIVEIRA, Bruna Padilha de. O essencial é invisível aos olhos: a emulação à escola produtivista e a subsunção das múltiplas jornadas das professoras no Programa de Ensino Integral de São Paulo. 2017. 141 f. Dissertação (Mestrado em Educação) - Universidade Estadual Paulista, Instituto de Biociências, Rio Claro, 2017.

OSTLER, Denise Almeida de. Impacto da Implantação do Programa Ensino Integral no atendimento a alunos com deficiência: desdobramentos em duas escolas públicas da Baixada Santista. 2017. 266 f. Tese de Doutorado. Universidade Metodista de São Paulo Escola de Comunicação, Educação e Humanidades. São Bernardo do Campo, 2017. 
PANTALEONI, Lucia Maria da Silva. O papel da Arte no Modelo de Ensino PEI Programa Ensino Integral -- na E.E. Cel. Raul Humaitá Villa Nova. São Paulo. 2016. 193 f. Dissertação (Mestrado em Educação). Universidade Presbiteriana Mackenzie Centro de Educação, Filosofia e Teologia. São Paulo, 2016.

PARENTE, Cláudia da Mota Darós. Políticas de Educação Integral em Tempo Integral à Luz da Análise do Ciclo da Política Pública. Educação e Realidade, Porto Alegre, v. 43, n. 2, p. 415-434, abr./jun. 2018a.

PARENTE, Cláudia da Mota Darós. A construção da escola de tempo integral: relações entre as opções político-pedagógicas da secretaria de educação (macro) e da escola (micro). Educação em Perspectiva, Viçosa, v. 9, n. 2, p. 330-346, maio/ago. 2018b.

PARENTE, Juliano Mota. Gerencialismo e performatividade na gestão educacional do Estado de São Paulo. 2016. 134 f. Tese (doutorado) - Universidade Estadual Paulista, Faculdade de Ciências e Tecnologia, Presidente Prudente, 2016.

PESSENTE, Adriana Maria D’Arezzo. A formação do professor protagonista no Programa Ensino Integral no Estado de São Paulo. 2016. 106 f. Dissertação (Mestrado Profissional em Educação). Universidade Federal de São Carlos, 2016.

PINTO, Helimara Vinhas Siqueira. 2016.127 fl. O olhar do jovem sobre o Programa Ensino Integral. Dissertação (Mestrado em Contextos, Práticas Sociais e Desenvolvimento Humano). Universidade de Taubaté. 2016.

QUARESMA, Daniel Gelini. Gestão democrática na escola de ensino integral: limites e possibilidades. 2015. 185 f. Dissertação (Mestrado Profissional em Educação) - Pontifícia Universidade Católica de São Paulo, São Paulo, 2015.

RAMOS, G. P. Racionalidade e gerencialismo na política educacional paulista de 1995 a 2014: muito além das conjunturas. Ensaio. Avaliação e Políticas Públicas em Educação, Rio de Janeiro, v. 24, n. 92, p. 546-578, jul./set. 2016.

REMIÃO, Isys Helfenstein. Educomunicação e Professores: uma análise sobre o uso das mídias na Escola Estadual Reverendo Augusto Paes de Ávila. 2017. Dissertação (Mestrado em Comunicação). Universidade Federal do Paraná. Curitiba, 2017.

SANTOS, Conceição Garcia Bispo dos. Análise do processo de avaliação do desempenho docente nas escolas do Programa de Ensino Integral (PEI) de São José do Rio Preto. 2017. 135 f. Dissertação (Mestrado em Educação) - Pontifícia Universidade Católica de São Paulo, São Paulo, 2017.

SÃO PAULO. Decreto n. 57.571, de 2 de dezembro de 2011. Institui, junto à Secreta- 
ria da Educação, o Programa Educação - Compromisso de São Paulo e dá providências correlatas. Disponível em: https://www.al.sp.gov.br/repositorio/legislacao/decreto/2011-57571-02.12.2011.html. Acesso em: 01 maio 2018.

SÃO PAULO. Lei Complementar n. 1.164, de 04 de janeiro de 2012a. Institui o Regime de dedicação plena e integral - RDPI e a Gratificação de dedicação plena e integral - GDPI aos integrantes do quadro do Magistério em exercício nas escolas estaduais de ensino médio de período integral [...]. Disponível em: http://www.al.sp.gov.br/repositorio/legislacao/ decreto/2012/decreto58140.15.06.2012.html. Acesso em: 01 maio 2018.

SÃO PAULO. Resolução SE n. 12, de 31 de janeiro de 2012b. Institui o Projeto Escola Estadual de Ensino Médio de Período Integral e estabelece diretrizes para a organização e funcionamento das Escolas Estaduais de Ensino Médio de Período Integral de que trata a Lei Complementar 1.164, de 4 de janeiro de 2012, e dá providências correlatas. Disponível em: http://www.mpsp.mp.br/portal/page/portal/Educacao/Legislacao/Estadual/Res\%20 SE\%2012\%20-\%20ProjetoEscolaEnsinoMédioIntegral.pdf. Acesso em: 1 maio 2018.

SÃO PAULO. Lei Complementar n. 1.191, de 28 de dezembro de 2012c. Dispõe sobre o Programa Ensino Integral em escolas públicas estaduais e altera a Lei Complementar $\mathrm{n}^{\mathrm{o}}$ 1.164, de 2012, que instituiu o Regime de dedicação plena e integral - RDPI e a Gratificação de dedicação plena e integral - GDPI aos integrantes do Quadro do Magistério em exercício nas escolas estaduais de ensino médio de período integral e dá providências correlatas. Disponível em: https://www.al.sp.gov.br/repositorio/legislacao/lei.complementar/2012/lei.complementar- 1191-28.12.2012.html. Acesso em: 01 maio 2018.

SÃO PAULO. Decreto n. 59.354, de 15 de julho de 2013a. Dispõe sobre o Programa Ensino Integral de que trata a Lei Complementar $\mathrm{n}^{\circ} 1.164$, de 4 de janeiro de 2012, alterada pela Lei Complementar $n^{\circ} 1.191$, de 28 de dezembro de 2012. Disponível em: https:/www. al.sp.gov.br/repositorio/legislacao/decreto/2013/decreto-59354-15.07.2013.html. Acesso em: 01 maio 2018.

SÃO PAULO. Resolução SE n. 49, de 19 de julho de 2013b. Dispõe sobre a organização e o funcionamento das escolas estaduais do Programa Ensino Integral, de que trata a Lei Complementar $n^{\circ} 1.164$, de 4 de janeiro de 2012, e dá providências correlatas. Disponível em: http://www.educacao.sp.gov.br/lise/sislegis/detresol.asp?strAto=201609010049. Acesso em: 01 maio 2018.

SÃO PAULO. Resolução SE n. 84, de 19 de dezembro de 2013c. Dispõe sobre a avaliação do desempenho de servidores do Quadro do Magistério no Programa Ensino Integral. Disponível em: http://www.educacao.sp.gov.br/a2sitebox/arquivos/documentos/731.pdf. Acesso em: 01 maio 2018.

SÃO PAULO. Resolução SE n. 67, de 16 de dezembro de 2014a. Dispõe sobre a gestão de pessoas, integrantes do Quadro do Magistério, nas unidades escolares do Programa Ensi- 
no Integral que especifica, e dá providências correlatas. Disponível em: http://siau.edunet. sp.gov.br/ItemLise/arquivos/67_14.HTM?Time=13/12/2017\%2014:24:57. Acesso em: 01 maio 2018.

SÃO PAULO. Diretrizes do Programa Ensino Integral. São Paulo: SEESP, [s.d].

SÃO PAULO. Diretrizes do Programa Ensino Integral- Caderno do Gestor. São Paulo: SEESP, 2014b.

SÃO PAULO. Modelo de gestão do Programa Ensino Integral. Caderno do gestor. São Paulo: SEESP, 2014c.

SÃO PAULO. Modelo de gestão de desempenho das equipes escolares. Caderno do gestor. São Paulo: SEESP, 2014d.

SÃO PAULO. Avaliação da Aprendizagem e Nivelamento. Caderno do gestor. São Paulo: SEESP, 2014e.

SÃO PAULO. Formação das equipes do Programa Integral. (Volume 1). São Paulo: SEESP, 2014f.

SÃO PAULO. Formação das equipes do Programa Integral. (Volume 2). São Paulo: SEESP, 2014g.

SOARES, Magda Becker; MACIEL, Francisca Izabel Pereira. Alfabetização. Brasília: MEC/INEP/Comped, 2000.

Dados das AUTORAS:

Cláudia da Mota Darós Parente

Doutora em Educação pela Universidade Estadual de Campinas. Campinas/SP - Brasil. Professora da Universidade Estadual Paulista "Júlio de Mesquita". São Paulo/SP- Brasil (DASE/Campus Marília e Programa de Pós-Graduação em Educação/Campus Presidente Prudente).claudia.daros@unesp.br

\section{Zelina Cardoso Grund}

Mestranda do Programa de Pós-Graduação em Educação da Universidade Estadual Paulista "Júlio de Mesquita" (Campus Presidente Prudente). Professora aposentada da rede estadual de ensino de São Paulo. zelina2509@terra.com.br

Submetido em: 20-6-2018

Aceito em: 7-5-2019 